\title{
PENINGKATAN KETERAMPILAN KOMUNIKASI DALAM BAHASA INGGRIS DI YAYASAN AL - HANIF PAMULANG TANGERANG SELATAN
}

\author{
${ }^{1)}$ Ariska ${ }^{2)}$ Asep Sugimat, ${ }^{3)}$ Hasanuddin Hamdani ${ }^{4)}$ Mia Siti Apriyanti, \\ ${ }^{5)}$ Reza Utami, ${ }^{6)}$ Sukma Rahmayani, ${ }^{7)}$ Tasya Shavira Trianda, ${ }^{8)}$ Welly Saputri Mahasiswa \\ Mahasiswa Prodi Sekretari D-III Universitas Pamulang \\ tasyasy@yahoo.com
}

\begin{abstract}
In this era of globalization, English is a language that is important for everyone when doing or learning something. By knowing and mastering English, it will increase your value, especially when if you decide to continue further with education and looking for a job. Mastering English also increases the chances of getting a good job in a international company in your country or getting a job abroad.
\end{abstract}

Keywords: english, communication, skills.

\begin{abstract}
ABSTRAK
Di Era Globalisasi ini, Bahasa Inggris adalah bahasa yang menjadi suatu hal yang penting bagi semua orang dalam melakukan ataupun mempelajari sesuatu. Dengan mengetahui dan menguasai bahasa Inggris, akan meningkatkan nilai dalam diri anda terutama saat melanjutkan pendidikan dan mencari pekerjaan. Menguasai Bahasa Inggris juga meningkatkan kesempatan untuk mendapatkan pekerjaan yang baik di perusahaan internasional di Negara Anda atau mendapat pekerjaan di luar negeri.
\end{abstract}

Kata Kunci: Bahasa Inggris, Meningkatkan, Pendidikan 


\section{PENDAHULUAN}

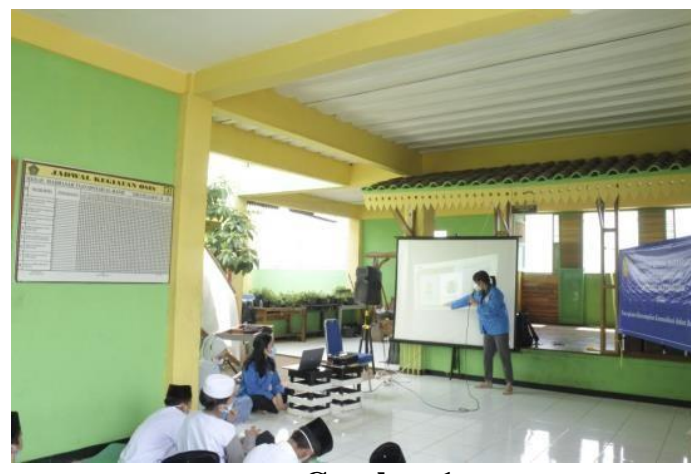

Gambar 1

Penyampaian Materi

Pengabdian Kepada Masyarakat adalah suatu kegiatan yang bertujuan membantu masyarakat tertentu dalam beberapa aktivitas tanpa mengharapkan imbalan dalam bentuk apapun. Secara umum program ini dirancang oleh berbagai universitas yang ada Indonesia untuk memberikan kontribusi nyata bagi bangsa Indonesia, khususnya dalam mengembangkan kesejahteraan dan kemajuan bangsa Indonesia.

Pengabdian Kepada Masyarakat merupakan salah satu bagian dari Universitas Pamulang. Di dalam sistem pendidikan Indonesia, bahasa Inggris telah diajarkan dan diperkenalkan sejak tingkat pendidikan yang sangat awal, seperti dalam kelompok bermain dan sekolah dasar. Bahasa Inggris juga menjadi materi dari testes ujian penting, seperti ujian nasional, ujian masuk perguruan tinggi, dan tes rekrutmen karyawan. Oleh karena itu, bahasa Inggris seharusnya sudah terintegrasi dalam pembelajaran siswa- siswa di sekolah-sekolah Indonesia. Sayangnya, faktanya tampak sebaliknya. Sangat mudah untuk menemukan siswasiswa Indonesia yang masih sulit untuk berkomunikasi dalam bahasa Inggris. Bahkan, setelah menghabiskan waktu yang cukup lama dalam belajar bahasa Inggris di sekolah dan mendapatkan berbagai tes bahasa Inggris dalam perjalanan pendidikan mereka, tetap saja masih banyak pelajar Indonesia yang belum mahir dalam berkomunikasi dengan menggunakan bahasa Inggris. Beberapa temuan hasil penelitian menunjukkan bahwa pelajarpelajar mempunyai masalah dalam aspek komunikasi lisan. Widiawati dan Cahyono (2006) mengidentifikasi beberapa masalah yaitu masalah linguistik (seperti grammar, vocabular, pronunciation), teknik komunikasi (seperti kefasihan dan hubungan interaksi), dan tak kalah pentingnya masalah psikologi (seperti motivasi dan kegelisahan). Hasil penelitian tersebut sejalan dengan hasil penelitian yang ditemukan oleh Nashruddin, Ningtyas, dan Ekamurti (2018) yang menggaris bawahi pengucapan kata atau frase, grammar yang tidak akurat, masalah pronunciation, dan motivasi yang lemah, semua itu adalah permasalahan yang dihadapi oleh pelajar Indonesia dalam pelajaran bahasa Inggris. 
Komunikas kebanyakan mengacu pada berbicara atau menulis. Sederhananya, komunikasi dapat digambarkan sebagai penyampaia pesan atau pertukaran informasi (McMahon, 1994). Ini berarti komunikasi akan terjadi ketika ada proses mengirim dan menerima pesan, atau dengan kata lain, ada proses produksi pesan (oleh pengirim) dan memahami pesan (oleh penerima). Dalam komunikasi lisan, prosesnya harus memastikan bahwa pesan dipahami oleh para pendengar dan pendengar merespon sesuai dengan maksud pembicara. Selanjutnya, juga harus memastikan respon yang diberikan dapat diinterpretasikan dan ditanggapi kembali oleh pengirim (Yu \& Ren, 2013). Ini menunjukkan bahwa pengirim tidak hanya mengirim pesan tetapi juga memastikan bahwa pesan diterima dan direspon oleh penerima secara tepat, demikian pula penerima, dia tidak hanya menerima tetapi juga memastikan bahwa respon yang diberikan dapat ditafsirkan dan ditanggapi kembali oleh sumbernya. Lebih lanjut, Richeit dan Strohner (2008) menyebutkan dua elemen yang harus disajikan dalam komunikasi, yaitu keefektifan dan kelayakan. Keefektifan adalah tentang bagaimana pengirim dan penerima mengakses makna yang dimaksudkan dalam komunikasi. Adapun kelayakan adalah tentang bagaimana komunikasi terikat oleh dimensi lain, seperti aturan, norma, atau harapan, termasuk dimensi yang disebutkan sebelumnya. Tujuan dalam berkomunikasi adalah untuk menjalankan pertukaran informasi dengan sukses, dimana ucapan yang dihasilkan oleh pembicara dapat dimengerti oleh pendengar. Menurut Richeit dan Strohner (2008), untuk mewujudkan hal itu, baik pembicara dan pendengar harus memiliki pengetahuan tentang unsur linguistik, seperti fonologi, morfologi dan sintaksis, meskipun diyakini bahwa pengetahuan tentang unsur-unsur linguistik itu saja tidak cukup tanpa keterampilan lain.

\section{METODE PELAKSANAAN}

Setelah kami melakukan survey Yayasan Al-Hanif Pamulang dan mengamati permasalahan apa saja yang ada, maka kami sepakat untuk mengambil judul "Peningkatan Keterampilan Komunikasi dalam Bahasa Inggris di Yayasan Al-Hanif Pamulang”. Langkah berikutnya yang kamu lakukan adalah membuat proposal PKM yang kami ajukan kepada Ketua Program Studi D-III Sekretari.

Proposal PKM yang diajukan kemudian akan di-review oleh reviewer untuk kemudian disetujui oleh Ketua Program Studi D-III Sekretari, maka kami melakukan berbagai persiapan terutama menyiapkan materi yang akan kami sampaikan pada kegiatan Pengabdian Kepada Masyarakat (PKM) untuk Peningkatan Keterampilan 
Komunikasi dalam Bahasa Inggris di Yayasan Al-Hanif Pamulang.

Berikut adalah tahapan-tahapan yang dilakukan oleh kelompok pelaksana Pengabdian Kepada Masyarakat (PKM):

1. Tahap Persiapan
a. Survei awal
b. Pemantapan dan penentuan lokasi sasaran

2. Penyusunan bahan atau materi meliputi : materi presentasi komunikasi dasar Bahasa Inggris.

3. Tahap Pelaksanaan Pelatihan Pada tahap ini akan dijelaskan mengenai cara Peningkatan Keterampilan Komunikasi dalam Bahasa Inggris di Yayasan AlHanif Pamulang dan memberikan praktek berupa memperagakan dialog dalam mengungkapkan maaf dalam Bahasa Inggris dan sesi tanya jawab dalam dialog ungkapan meminta dan ungkapan rasa terima kasih dalam Bahasa Inggris.

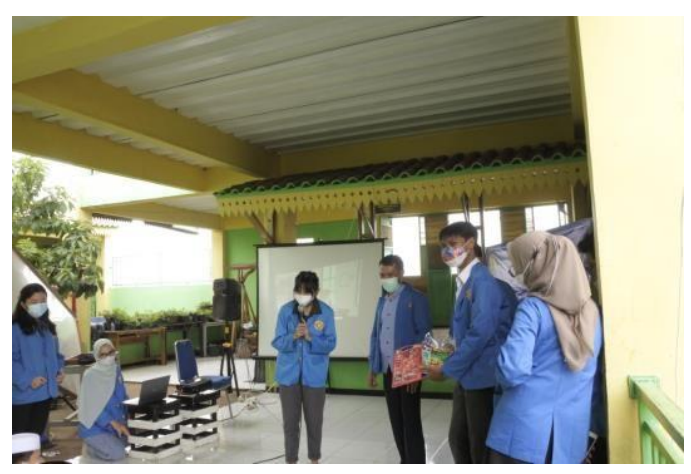

Gambar 2 Sesi Tanya J Jawab

\section{PEMBAHASAN DAN HASIL}

Pembahasan dan hasil dari Peningkatan Keterampilan Komunikasi dalam Bahasa Inggris di Yayasan Al-Hanif Pamulang adalah dengan penyampaian materi komunikasi dasar Bahasa Inggris dan juga praktek komunikasi dasar Bahasa Inggris. Adapun materi yang disampaikan adalah sebagai berikut:

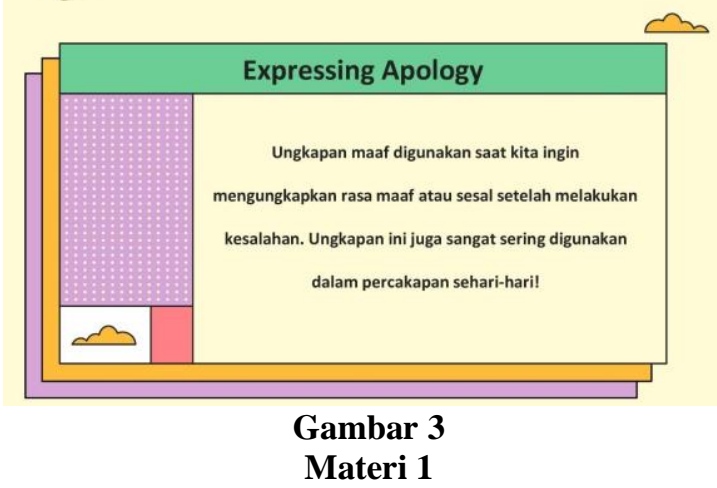

Expressing gratitude atau menyampaikan rasa terima kasih. Dalam bagian ini dijelaskan bahwa ada beberapa cara untuk mengungkapkan "terima kasih" dalam Bahasa Inggris selain "thank you" dan bagaimana cara meresponnya.

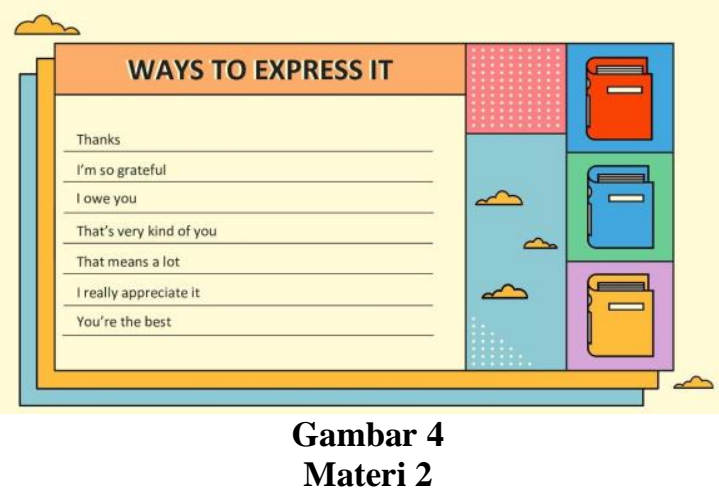

Selanjutnya ada materi Expressing Apology atau ungkapan maaf. Dalam bagian ini dijelaskan bagaimana 
mengungkapkan maaf dalam bahasa inggris selain dengan "sorry".

\section{KESIMPULAN DAN SARAN}

Berdasarkan hasil pelaporan dan pembahasan yang telah diuraikan, maka dapat diambil kesimpulan sebagai berikut:

1. Mempelajari bahasa Inggris itu sangat penting bagi semua orang karena di era globalisasi ini bahasa Inggris adalah bahasa yang paling umum dipakai di seluruh dunia.

2. Materi yang kami berikan tentang peningkatan keterampilan komunikasi dalam bahasa Inggris diharapkan mampu menambah pengetahuan dan berguna bagi para siswa/i baik untuk sekarang maupun masa yang akan datang.

3. Selama pemberian materi dikelas Siswa/i sangat antusias, terutama dalam sesi tanya-jawab karena hal tersebut mereka dapat menggali informasi dan pengetahuan lebih banyak lagi.

Setelah melaksanakan Pengabdian Kepada Masyarakat (PKM) dengan tema Peningkatan Keterampilan Komunikasi dalam Bahasa Inggris penulis memberikan saran:
1. Agar siswa/i lebih giat dalam belajar dan memahami apa yang telah diajarkan selama PKM maupun selama mereka belajar di sekolah.

2. Lebih mengembangkan potensi yang mereka miliki agar nantinya dapat berguna dalam dunia kerja khusunya di era modern ini.

\section{DAFTAR PUSTAKA}

Awwaabiin, S. (2021). $15 \quad$ Cara Meningkatkan Kemampuan Bahasa Inggris dengan Cepat online di https://www.duniadosen.com/carameningkatkan-kemampuan-bahasainggris/ diakses pada Minggu, 20 Oktober 2021.

Naiborhu, R. (2019). Upaya Meningkatkan Keterampilan Berbicara Bahasa Inggris Melalui Metode Permain Peran. Jurnal Global Edukasi: Vol. 3, No. 1, Ags 2019, hlm. $7-12$

Josua Bire, E. S. N. H. T. F. (2014). Faktor-Faktor yang Mempengaruhi Rendahnya Kecakapan Berbicara Mahasiswa Program Studi Bahasa Inggris. Perspektif Ilmu Pendidikan, 28(2), 140. https://doi.org/10.21009/pip.282.9

Putri, S. O. (2017, December). Faktor Yang Mempengaruhi Kemampuan Berbahasa Inggris Mahasiswa Pendidikan Administrasi Perkantoran (No. 154914286). Universitas Yogyakarta. 